\title{
Histological Studies on the Conduction System in 14 Gases of Right Bundle Branch Block Associated with Left Axis Deviation
}

\author{
Masaya Sugiura, M. D., Ryozo Okada, M. D., Keisuke \\ Hiraoka, M. D., and Shinichiro Ohkawa, M. D.
}

\begin{abstract}
SUMMARY
The conduction system was histologically examined in 14 cases of right bundle branch block associated with left axis deviation. Twelve cases showed marked degeneration of the central fibrous body, degeneration and interruption (fibrosis, calcification and fatty changes) of terminal portion of the bundle of His, proximal portions of the both bundle branches and intermediary portions of the right bundle branch and the anterior radiation of the left bundle branch. Some increase of acid mucopolysaccharide was frequently found in the blocked lesions, which suggested an accumulation of mechanical strain as a pathogenesis of the injuries in the conduction system. Two cases showed extensive myocardial infarction which gave total necrosis on the peripheral part of bilateral bundle branches. Histological basis of RBBB with LAD was concluded as a kind of bilateral bundle branch block.
\end{abstract}

\section{Additional Indexing Words:}

Bilateral bundle branch block Parietal block A-V node A-V bundle Central fibrous body Aging Myocardial infarction

Left bundle branch block A-V block

TNGIDENGE of left axis deviation has been believed to increase by aging. ${ }^{11-5)}$ Screening of the electrocardiograms in the aged further clarified a high incidence of electrocardiographic combination with right bundle branch block. ${ }^{5)}$ There were 39 cases of right bundle branch block associated with left axis deviation (RBBB with LAD) among a total of 2,158 electrocardiograms from the periodic mass-survey in the aged over 60 during 1966 and 1967. Recently there have been several papers about this type of conduction disturbance and much attention was focused on its pathogenesis. ${ }^{6)-15}$ ) The purpose of this study was histological and partly histochemical examination of conduction system on this peculiar form of conduction disturbance.

Departments of Internal Medicine and Pathology, Yoiku-in Hospital, Tokyo Municipal Home for the Aged, Itabashi, Tokyo.

Recieved for publication October 19, 1968. 


\section{Materials and Methods}

A total of 42 cases of RBBB with LAD were collected from clinical records of the Yoiku-in Hospital during recent 7 years, of which 20 cases died and 14 cases were autopsied. There were 7 men and 7 women, with their age ranging from 71 to 92 years (Table I.) Underlying diseases included 7 cases of hypertension, of whom 2 cases developed ccrebral blecding, 3 cases of myocardial infarction (2 cases of anterior and one case of diaphragmatic infarction), each one case of mitral insufficiency, complete $\mathrm{A}-\mathrm{V}$ block, pneumonia and pulmonary tuberculosis. A total of 62 electrocardiograms were available for analysis of the time of onset and development of RBBB with LAD.

Pathological examination was made according to Lev's method.16) The specimens were carefully observed using a magnifying glass, concerning calcification, atheromatous change, and fibrosis in the conduction system. Some of specimens were fixed by $10 \%$ cetyl-trimethyl-ammonium chloride and formalin for acid mucopolysaccharide (aMPS) study. The specimens were embedded into paraffine and were cut at $7 \mu$. by usual manner. Each of twentieth section was retained in a procedure of serial sectioning of these blocks, which totaled 2,540 preparations. These preparations were stained by hematoxylin-eosin, Elastica van Gieson, periodic acid Schiff, alcian blue, toluidine blue and Reinhart's modification of dialysed iron method.

\section{RESULTS}

(I) Electrocardiographic findings (Table I, Fig. 1): Eleven cases showed sinus rhythm. Complete heart block, A-V nodal rhythm and atrial fibrillation were found in each one case. Duration of QRS was found from 0.12 to $0.16 \mathrm{sec}$. Electrical axis on the frontal plane ranged from minus 30 to minus 80 degrees, with an average of minus 56 degrees. QRS pattern in lead I was rs (Type $\mathrm{Va}^{10}$ ) in 7 cases, $\mathrm{qRs}$ (Type $\mathrm{V}_{\mathrm{b}}$ ) in 6 and $\mathrm{R}$ (Type VI) in one. QRS pattern in lead $V_{1}$ was $r s R^{\prime}$ in 6 cases, $r R^{\prime}$ in $3, R^{\prime}$ in $2, q^{R}$ in $2, \mathrm{R}$ in 1 , with their ventricular activation time from $0.07 \mathrm{sec}$. to $0.12 \mathrm{sec}$. QRS pattern in lead $V_{6}$ was $q R s$ in 5 cases, $R s$ in 5 , rs in 3 and $q R$ in onc with their ventricular activation time from 0.02 to 0.05 scc. Right ventricular hypertrophy in 11 cases, and left ventricular hypertrophy in 4 . PR interval was available in 11 cases out of which first degree A-V block was found in one case. Duration of RBBB with LAD in electrocardiogram ranged from 1 day to 9 years. Sequence of occurrence of RBBB and LAD was chronologically analyzed. RBBB preceded in 2 cases (Case 5, 9), LAD preceded in 2 (Case 1, 12), slight tendency of LAD (axis between 0 and minus 29 degrees) changed to RBBB and definite LAD simultaneously in 2 (Case 2,6). RBBB and LAD occurred simultaneously in 2 cases (Case 13, 14) of acute myocardial infarction. Remaining 6 cases showed both findings since the first 


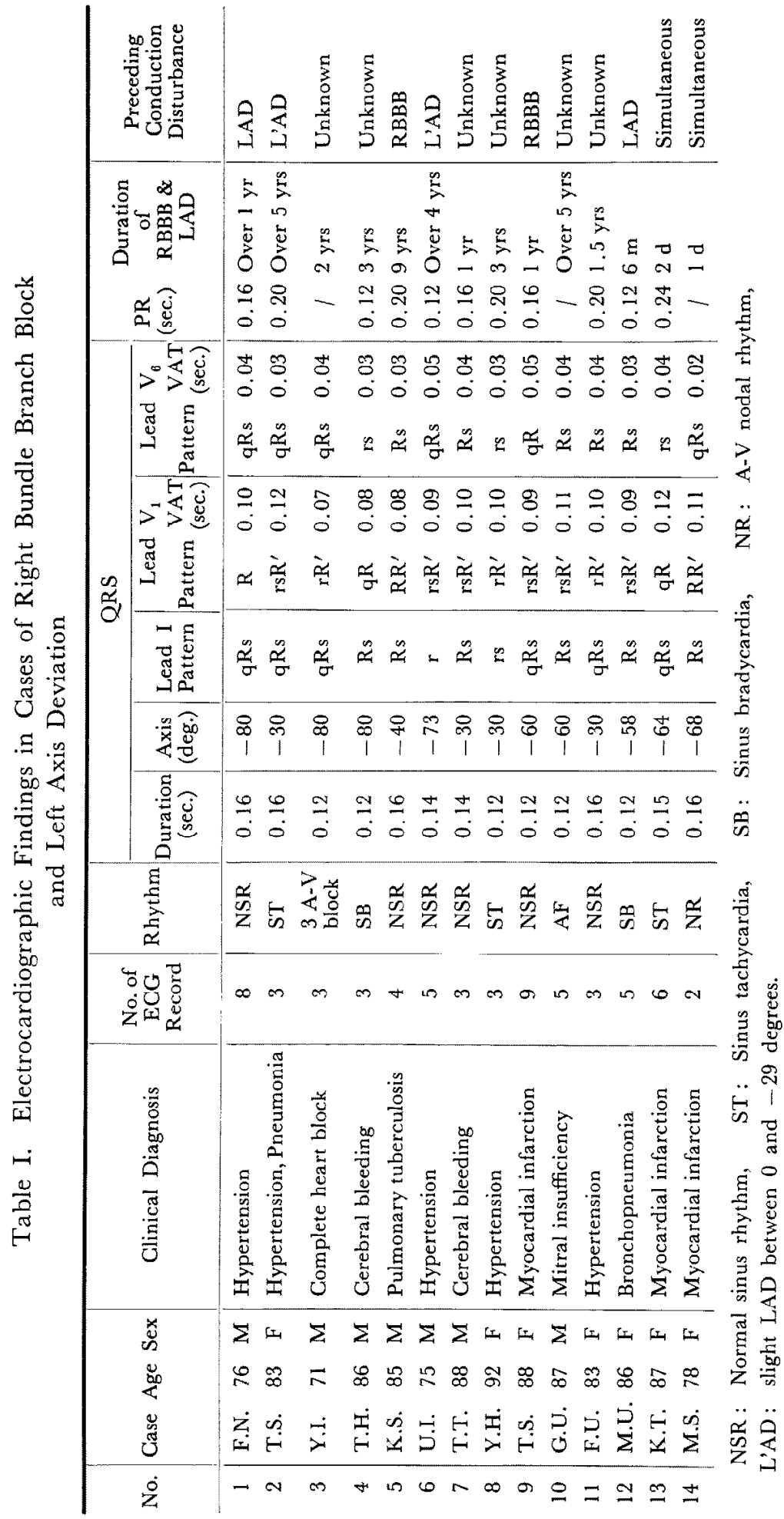




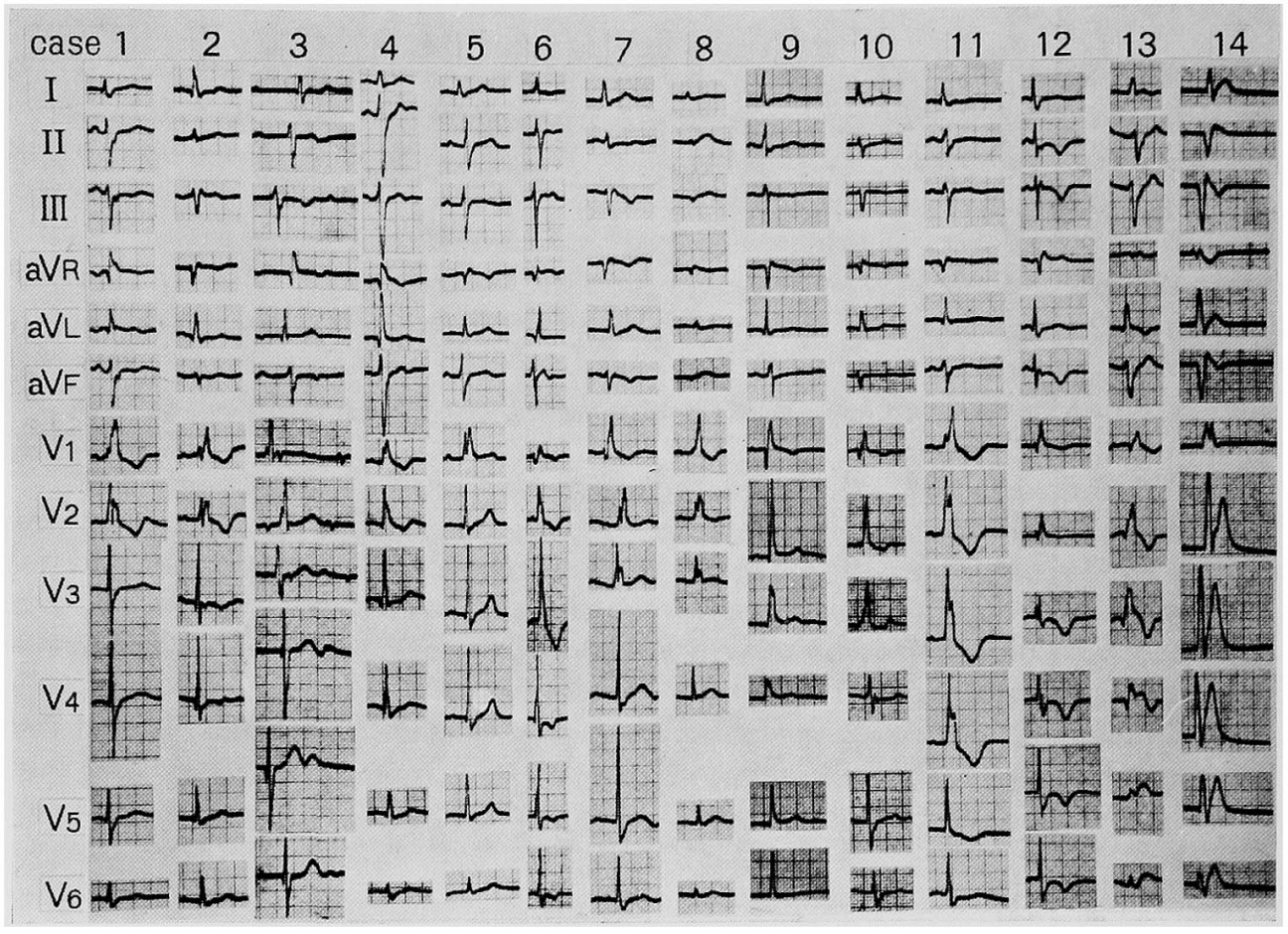

Fig. 1. Electrocardiogram in 14 cases of RBBB with LAD.

available electrocardiographic record and could not be analyzed about their time sequence.

(II) Pathological and histological findings (Table II): Heart weight ranged from $270 \mathrm{Gm}$. to $510 \mathrm{Gm}$. with an average of $365 \mathrm{Gm}$, among which cardiac hypertrophy over $350 \mathrm{Gm}$. was found in 7 cases.

Fourteen cases were divided into 3 groups according to the site of lesions in the both bundle branches.

(1) Bifurcation type: In 12 cases various degrees of degenerations were found in the central fibrous body, including hyalinoid and/or fibrinoid degenerations, and calcification with some increase of aicd mucopolysaccharides (Fig. 2a, b). Pathological changes were scarcely found in the A-V node, and penetrating portion of the bundle of His. The distal branching portion of the bundle of His was the main portion of degenerative changes with disappearance of the conduction cells including proximal portions of right bundle branch and anterior radiation of left bundle branch (Fig. 2a, 3). Nature of the degeneration was mainly fibrosis, which was stained positive by the method for staining aMPS (Fig. 2a, b). Thus a group of changes concentrated on the distal part of A-V bundle might be called as " bifurcation type", whose pure type was found in 2 cases (Case 1,2). 
Vol. 10
No, 2

RBBB WITH LEFT AXIS DEVIATION

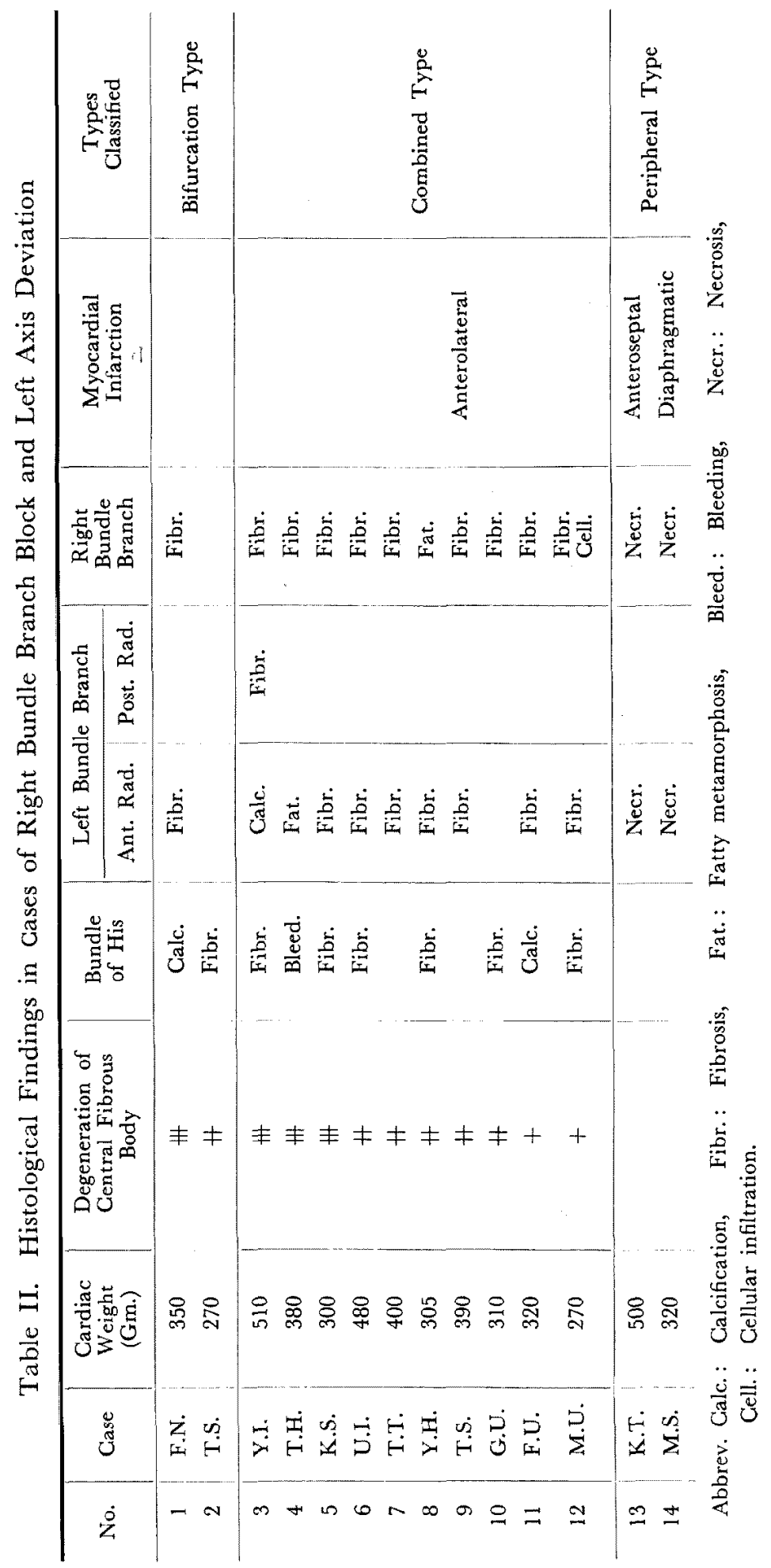




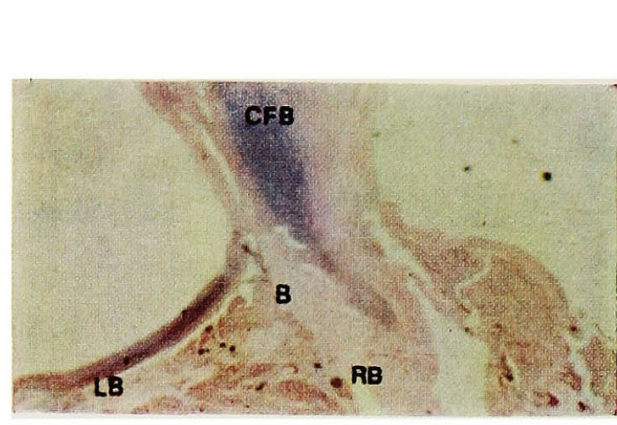

a

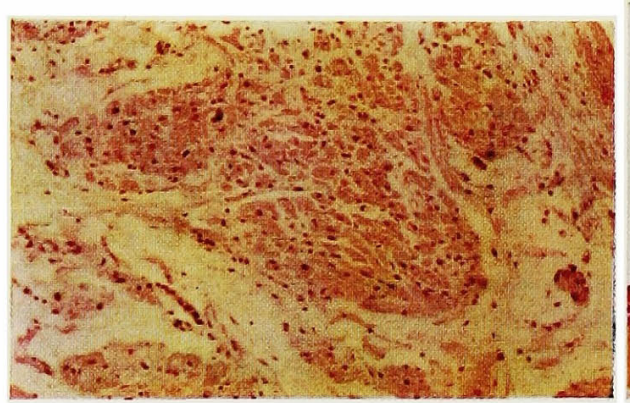

c

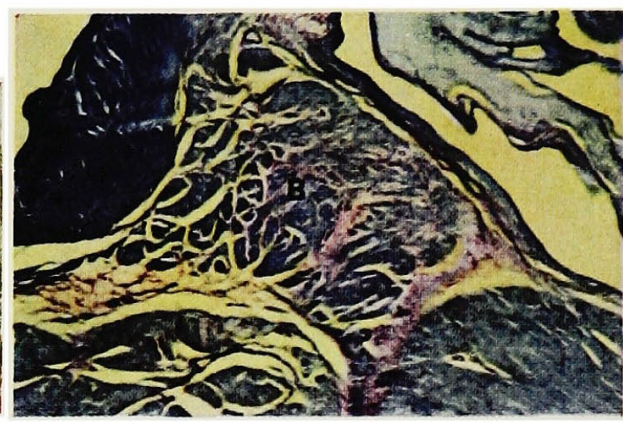

b

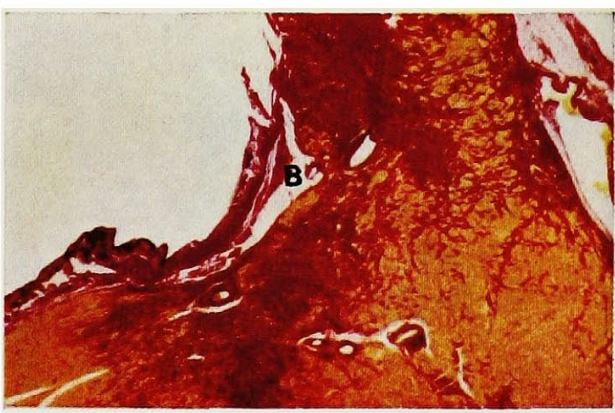

d

Fig. 2. A-V bundle and central fibrous body in specific staining methods.

a) Case 7. (Alcian blue, $\times 13$ ) Branching portion of the A-V bundle. Its interstitial spaces were stained with bluc tone as central fibrous body, which showed marked accumulation of aMPS. The right-sided portion of the bundle (for right bundle branch) showed a reduced staining.

b) Case 12. (Toluidine blue, $\times 40$ ) Branching portion of the $\mathrm{A}-\mathrm{V}$ bundle and proximal portion of posterior radiation of the left bundle branch. Interstitial spaces within the bundle showed marked metachromasia. Central fibrous body was similarly stained.

c) Case 12. (H. E., $\times 100)$ Conduction cells within the bundle of His showed some degeneration. (Right lower portion of Fig. 2b)

d) Case 5. (Elastica van Gieson, $\times 13$ ). Branching portion of the bundle of His and marked septal fibrosis.

(2) Intermediary type: The other 10 cases had not only bifurcation type lesions, but also lesions at the "intermediary" zone of bilateral bundle branches, which could be called as "combined type". The intermediary zone corresponds to the second portion (middle third) of the right bundle branch situated deep within the myocardium (Fig. 4 c), and to the subendocardial portion of the left bundle branch at the upper end of the interventricular septum (Fig. 4 b). Nature of the lesions were mainly fibrosis (Fig. $4 \mathrm{c}$ ), occasionally fatty metamorphosis (Fig. 4 b), and rarely severe calcification 


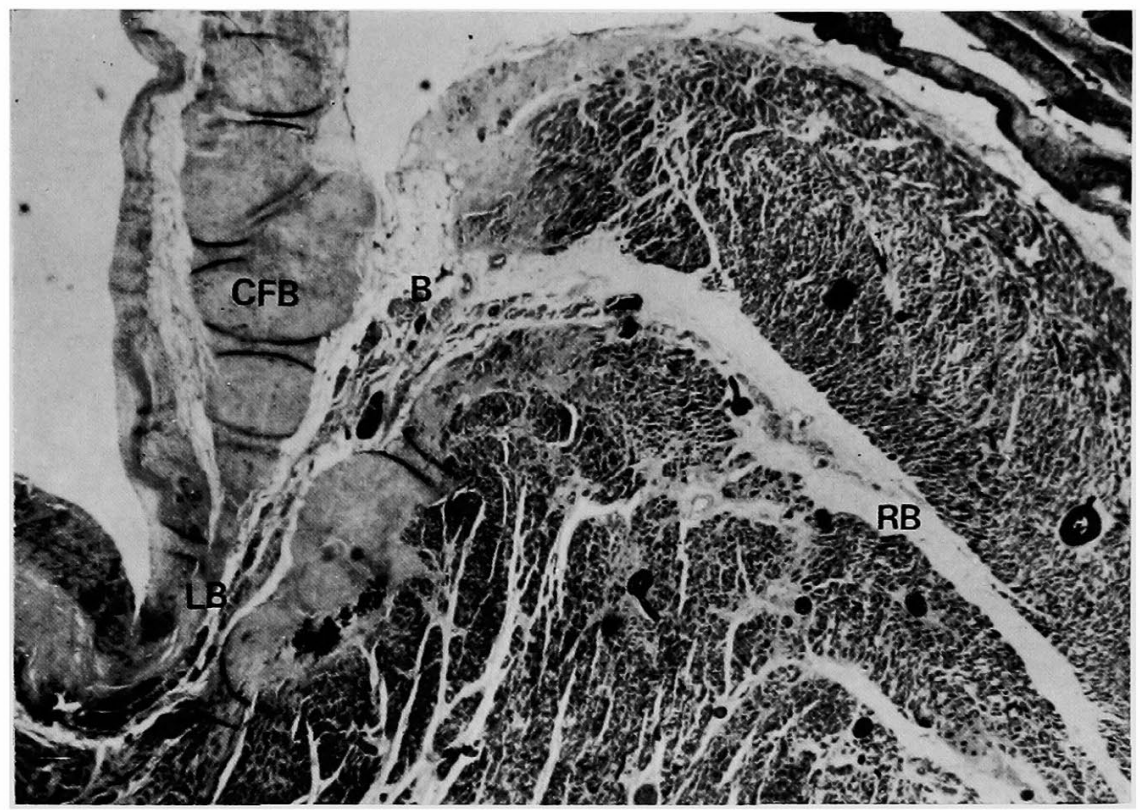

Fig. 3. Bifurcation of the A-V bundle. Case 1. (H. E. $\times 13)$ Branching portion with right bundle branch and anterior radiation of the left bundle branch were seen on both sides. Note severe septal fibrosis with calcification and fatty metamorphosis around the bundle.

replacing the bundle and LBB (Fig. 4 a). Fibrotic region was stained blue by alcian blue method. In one case (Case 12), there was an area of cellular infiltration with monocytes at the portion of complete interruption of right bundle branch (Fig. $4 \mathrm{~d}$ ). These intermediary zone started 5 to $10 \mathrm{~mm}$. distal from the bifurcation and continued for 5 to $10 \mathrm{~mm}$. without any changes in the more distal portions. Case 9 showed fibrosis in the right bundle branch, and no abnormalities in the left bundle branch. This case had localized hypoplastic left ventricle accompanied by rudimentary right coronary artery, which category was reported previously and discussed on the genesis of left axis deviation. ${ }^{17)}$

(3) Peripheral type: In 2 cases myocardial infarction produced the conduction disturbance. In Case 13, there was an extensive anteroseptal infarction and in Case 14, posterior infarction was found. Both necrotic areas involved the peripheral portions of bilateral bundle branches (Fig. 5a, b). Anterolateral myocardial infarction in Case 9 did not have any relationship with the conduction defect, which developed one year prior to infarction, and changes were classified as combined type.

Electrocardiographic subtypes according to Lepeschkin ${ }^{10)}$ did not show specific difference in histological aspects. Acid MPS study revealed some ac- 


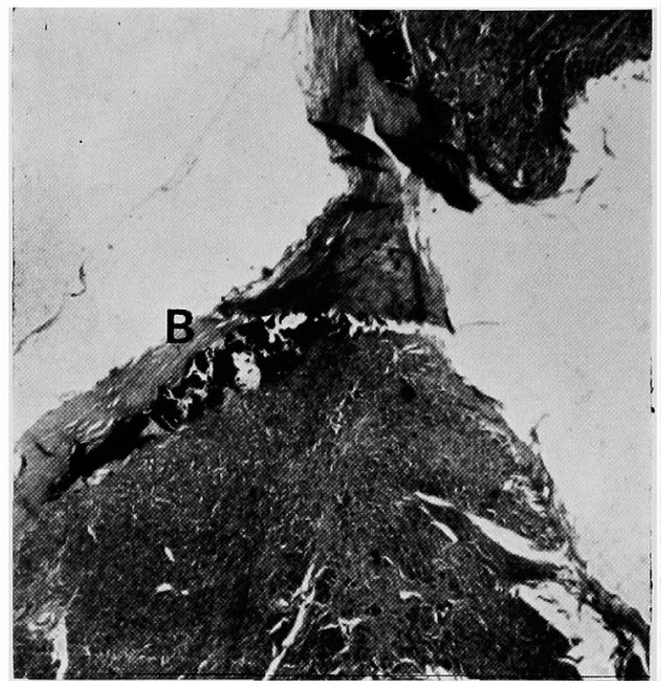

a

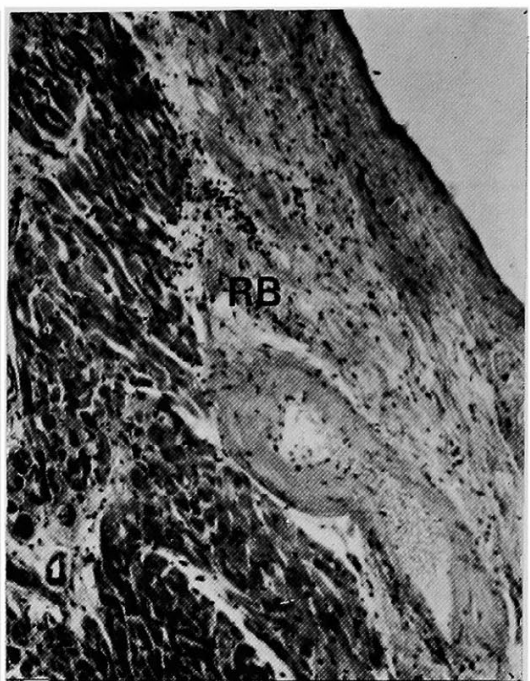

b

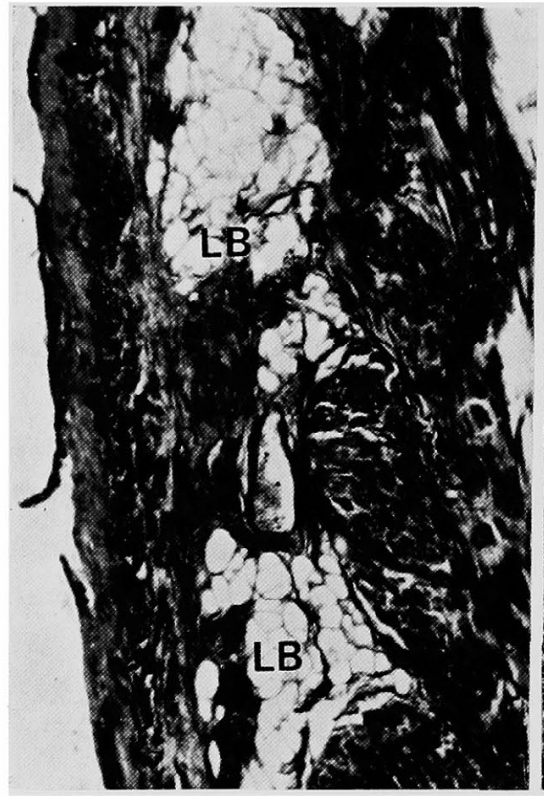

C

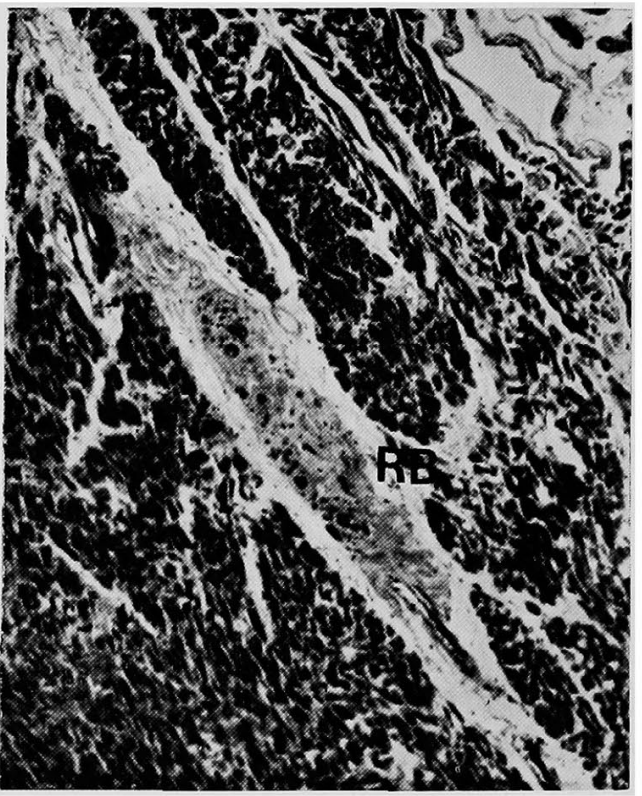

d

Fig. 4. a) Case 3. (H. E. $\times 13$ ) Branching portion of the bundle of His, almost replaced by marked calcification.

b) Casc 12. (H. E. $\times 40)$ Monocyte infiltration seen in the intermediary portion of the right bundle branch.

c) Gase 4. $(\mathrm{EvG} \times 40)$ Fatty metamorphosis interrupted intermediary zone of left bundle branch.

d) Case 9. (H. E. $\times 40)$ Fibrosis replaced conduction cells in the intermediary zone of the right bundle branch. 


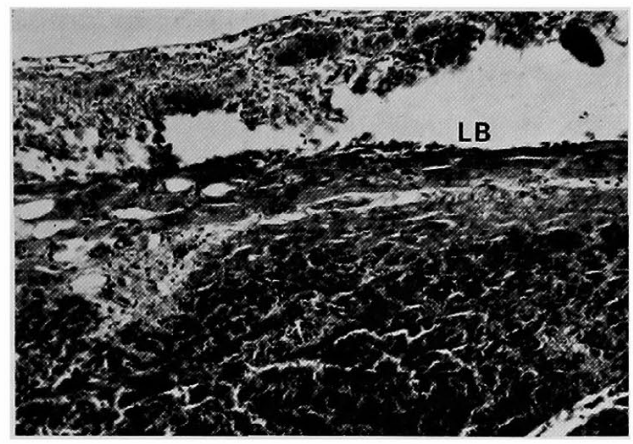

a

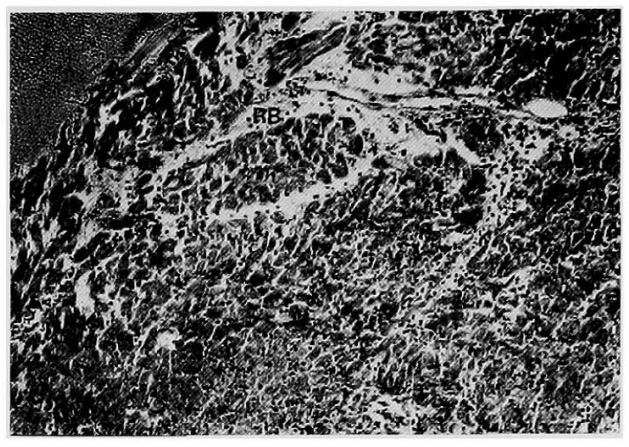

b

Fig. 5. Peripheral zones of both bundle branches, where massive myocardial infarction involved.

a) Case 13. (H. E. $\times 100)$ Necrosis of left bundle branch.

b) Case 13. (H. E. $\times 100)$ Necrosis of right bundle branch.

cumulation of alcian blue staining and positive metachromatic substances in the conduction system at either bifurcation of bundle of His, and intermediary zone of bilateral bundle branches. The accumulated aMPS seemed to have correlation to degeneration of conduction cells and loose fibrosis around them.

\section{Comments}

A combination of RBBB with LAD was noted as "masquarading left bundle branch block" by Richman and Wolff in 1953.6) They emphasized an importance of posteroseptal myocardial infarction in their 5 autopsy cases. There was only one case, whose conduction disturbance could be explained by the posteroseptal infarction in our 14 cases (Case 14). The first histological proof was obtained by Unger et al. ${ }^{7)}$ and Lenègre8) in 1958 . Unger et al. showed extensive lesions of both bundles in 2 cases of masquarading bundle branch block, and concluded this type as a kind of bilateral bundle branch block. Lenègre reported 7 cases of this type of conduction block under the heading of right bundle branch block, ${ }^{8}$ ) whose histological findings showed various lesions in the left bundle branch besides right bundle branch. Later in 1964, he reported a total of 12 cases of atypical right bundle branch block having a left axis deviation from minus 60 to minus 90 degrees, and concluded as histological findings complete right bundle branch block and incomplete left bundle branch block or left ventricular parietal block. ${ }^{\prime \prime}$

In our report on 14 cases, it should be emphasized that this conduction disturbance had lesions in the anterior radiation of the left bundle branch besides right bundle branch, so to speak a kind of bilateral bundle branch block. A lesion introducing bilateral bundle branch block should be exten- 
sive, if the lesion was located peripherally. On the contrary, even a small lesion has significant influence, if the lesion was located centrally. In fact, a degenerative change at the bifurcation was the essential features in 12 cases, and there was only 2 cases, in whom it must be explained by more peripheral lesions extending to the interventricular septum either from anterior or posterior infarction.

Four cases reported by Mashima, ${ }^{18)} 26$ cases by Blondeau and Lenègre, ${ }^{19}$ ) 26 cases of Lasser et al., ${ }^{14}$ ) Case 3 in this study presented complete A-V block or Adams-Stokes attacks and histologically examined cases among these showed right and left bundle branch block. From these discussions, the combination of RBBB with LAD is a kind of bilateral bundle branch block and has a possibility to proceed to the complete A-V block via the complete bilateral bundle branch block. In fact Case 3 showed lesions not only in the right bundle branch and anterior radiation of left bundle branch, but also in the posterior radiation of the left bundle branch.

Recently Pruitt and collaborators ${ }^{11)}$ reported a shift of electrical axis to the left by a section of the anterior radiation of left bundle branch in dogs and baboons. Additional section of right bundle branch resulted in a simultaneous appearance of RBBB and remarkable LAD. ${ }^{12), 13)}$ Occurrence of RBBB eliminated the electrical force directing to the left ventricular anterior wall from the distal right bundle branch, and posterior radiation of left bundle branch was forced to play a main role for excitation of bilateral ventricles. Preceding mild LAD (L'AD) between 0 and minus 29 degrees turned to a marked degree LAD simultaneously with onset of RBBB was verified in 2 cases (Case 2,6) in this study, which would be a clinical reflection of Pruitt's experiments. As for the significance of L'AD, at least a case of RBBB with L'AD could be cited, ${ }^{20)}$ who died of small septal perforation due to myocardial infarction. Studies on conduction system showed complete interruption of right bundle branch and partial block of left bundle branch by calcification.

Etiological problems of these conduction disturbances found in the aged have been controversial as for either ischemia or inflammation. Lenègre, ${ }^{8)}$ however, stated that these were of unknown etiology except those due to myocardial infarction and pointed out a possibility by mechanical strain on the conduction sytem from observations on cases of LBBB, which was located within extremely limited area between the bifurcation and the subendocardial layer, and named this effect as "microtraumatisme". The authors agree with his concept and further would like to apply it to this form of conduction disturbance by explaining the relationship between 3 favourite portions and the mechanical strains on them. The first is the distal bifurcation of bundle of His, which completed its penetration through the central fibrous body and where 
was formed a junction between the hard non-contracting central fibrous body and relatively soft contracting myocardium. The second is the upper third of right bundle branch, which makes rather sharp flexion deep within the myocardium. Mechanical strain produced by myocardial contraction on each portion of the right bundle branch might be increased at the turning point because of discordant direction of the conduction system and the usual working muscle. The third is the subendocardial portions of the left bundle branch at the outflow tract of left ventricle, especially at the upper-most part of interventricular septum. Rapidly ejected blood might have a lifting effect to the endocardium at the outflow tract, which could make some harmful effect to the conduction system running just below the endocardium. Thus, 12 out of 14 cases could be explained etiologically by an accumulation of mechanical strain. Another 2 cases showed an extensive myocardial infarction including the peripheral portions of bilateral bundle branches.

Another support for the hypothesis of mechanical strain was found in accumulated aMPS, increasing in the region of fibrosis inducing interruption of the conduction system. Accumulation of this material usually occurs in the inflammatory lesions or in the region of strong mechanical strains. ${ }^{21)}$ Gellular infiltration was found in only one case, and was located at the site of complete interruption of the right bundle branch and mainly consisted of monocytes without any similar changes in the surrounding myocardium, suggesting strongly a non-specific reaction accompanying degenerative changes. Accumulation of aMPS seen in this group of conduction disturbance was assumed to be related with increased mechanical strains. Intracardiac structures, which receive the strongest mechanical strains are cardiac valves and central fibrous body as supporting tissues. Increased aMPS could easily infiltrate into the conduction cells and might give some harmful effect to induce their degeneration. Accordance of predilection sites of degenerative changes in the conduction system, sites of mechanical strains and accumulation of aMPS in these portions strongly advocate our hypothesis.

\section{ACKNOWLEDGEMENT}

Acknowledgement is made to Miss Tatsuko Horiuchi for her technical assistance.

\section{REFERENCES}

1. Curd, G. W., Jr., Hicks, W. M., Jr., and Gyorkey, F. : Am. Heart J. 62 : 462, 1961.

2. Eliot, R. S., Millhon, W. A., and Millhon, J. : Am. J. Cardiol. 12 : 767, 1963.

3. Pryor, R. and Blount, S. G., Jr.: Am. Heart J. 72 : 391, 1966. 
4. Blackburn, H., Vasquez, C. L., and Keys, A. : Am. J. Cardiol. 20 : 618, 1967.

5. Sugiura, M., Okada, R., Iizuka, T., Kubo, F., Hiraoka, K., and Ohkawa, S. : Saishin-igaku $23: 1460,1968$ (in Japanese).

6. Richman, J. L. and Wolff, L. : Am. Heart J. $47: 383,1954$.

7. Unger, P. N., Lesser, M. E., Kugel, V. H., and Lev, M. : Circulation 17 : 397, 1958.

8. Lenègre, J.: Contribution á l'étude des blocs de branche. J.-B. Baillière et fils, Paris, 1958.

9. Lenègre, J.: Prog. Cardiovasc. Dis, 6 : 409, 1964.

10. Lepeschkin, E.: Prog. Cardiovasc. Dis. 6: 445, 1964.

11. Watt, T. B., Jr., Murao, S., and Pruitt, R. D. : Am. Heart J. 70 : 381, 1965.

12. Watt, T. B., Jr., Freud, G. E., Durrer, D., and Pruitt, R. D. : Círculat. Res. 22 : 57, 1968.

13. Pruitt, R. D. : Circulation $36: 625,1967$.

14. Schloff, L. D., Adler, L., Donoso, E., and Friedberg, C. K. : Circulation 35 : 790, 1967.

15. Lasser, R. P., Haft, J. I., and Friedberg, C. K. : Circulation 37 : 429, 1968.

16. Lev, M., Widran, J., and Erickson, E. E. : Arch. Path. 52 : 73, 1951.

17. Sugiura, M., Okada, R., Morii, T., and Shimada, H. : Jap. Heart J. 9 : 509, 1968.

18. Mashima, S., Harumi, K., Sato, G., Yanai, Y., and Ueda, H.: Jap. Heart J. 4 : 303, 1963.

19. Blondeau, M., et Lenègre, J. : Arch. mal. coeur. 57 : 1, 1964.

20. Sugiura, M., Okada, R., Iizuka, T., Ohkawa, S., Shimada, H., and Nakanishi, A.: Jap. Heart J. $9: 411,1968$.

21. Okada, R., Rosenthal, I. M., Scarvelli, G., and Lev, M.: Arch. Path. 84: 20, 1967. 